\title{
Editorial
}

\section{The IDM goes digital}

Journal of Direct, Data and Digital Marketing Practice (2011) 13, 1-2. doi:10.1057/dddmp.2011.24

You may have noticed our new brand identity and new name: The Institute of Direct and Digital Marketing on the front cover. This was launched a couple of months ago and the reaction from our customers and members has been extremely positive. The bright colours are seen to give the IDM a fresher, more contemporary image while the name change puts the IDM firmly at the forefront of digital training. Both Robin and I really hope you like the new cover design; please let us know your opinion.

The question many people ask us, 'Why the change?'

Firstly, we recognized every business needs to constantly change and it was time for The IDM to redefine its purpose and market relevance given the rapidly changing marketing technologies. Equally, The IDM business model has dramatically changed over the past 5 years, with 60 per cent of our business now being digital marketing.

Given the impact of digital technologies on marketing and the changes to the IDM business model, it was felt that it was imperative that The Institute of Direct and Digital Marketing as an organisation reflects the new values and priorities of the marketing profession. A name change to The IDM is a clear indication to the marketplace of our new positioning as the only government-approved institute for digital marketing. We will retain the shorthand version of IDM, given the brand's 25-year heritage, the ' $\mathrm{D}$ ' representing both direct and digital.

From the Journal's perspective, it will mean that the editorial board will be vigorously discussing whether the Journal should remain in hard copy or go online, with the savings spent to add value to our readership. This is a very vexed question and no decisions will be made without consultation with our readership.

Back to this edition of the Journal - the first article covers a very topical subject: social CRM.

Today, companies must contend with the huge and growing social web, where customer experiences and opinions are shared on a massive scale, and corporate reputations can be ruined almost instantaneously.

Navigating this new world requires a new way of approaching customer relationship management, commonly called social CRM. In addition to their traditional CRM tools and processes, companies must rethink their product, channel and customer strategies in order to build an entirely new relationship with their customers through greater transparency.

The article gives an insight into social CRM, and at the end a simple three-step approach every company should follow.

The second article is titled CRM in a Web 2.0 world: Using corporate blogs for campaign management. In this paper, the authors explore the use of a corporate blog as a CRM tool to be utilized for contributing to the CRM functionalities of campaign management, customer service and support, and support to marketing communication and product development for aiding the organization in developing consumer-targeting strategies appropriately.

Our third article, by Pete Comley and Jon Beaumont, is on virtual surveys. Nearly a decade ago, the lead author wrote an article for this publication titled Online Survey Techniques. In Part II he looks back at how the market has changed and provides an update on the developments in qualitative online market research. 
In the final article, Adrian Gregory, Chairman of DQM Group and Chair of the IDM Data Council, gives us Part II of Data Governance - protecting and unleashing the value of your customer data assets.

In a previous edition of the Journal, Adrian made the case for investing in your customer data and outlined an effective approach for assessing your data capability and maximizing the long-term value of your customer data assets. This second paper (in a series of three) focuses on how organizations of any size can significantly improve their data quality and begin to use their data for greater intelligence to drive successful business strategies. It focuses on fixing the key priorities, which are likely to be closely associated with data quality and are likely to deliver the greatest returns.

Our case study this quarter is the story of rebuilding a subscriber base and revitalizing one of Britain's best-loved and most important brands: Which? This journey — one that has taken 6 years to date - has completely transformed Which?'s marketing activity and results, and examines the lead media channel that has driven its success.

In conclusion, Robin and I hope you like the rebranding. We hope to keep the editorial as fresh as the new brand and your contributions and views are really welcome. 